\title{
End-of-life decision making for cancer patients in an intensive care unit
}

\author{
M Tavares", I Neves, F Coelho, O Afonso, A Martins, F Faria \\ From ESICM LIVES 2015 \\ Berlin, Germany. 3-7 October 2015
}

\section{Introduction}

Patients with advanced malignances are at a high risk of developing complications that lead to an Intensive Care Unit (ICU) admission. Despite improvements in ICUlevel care, mortality rates for some patients remain especially high. Limitation of therapy is an integral component of high-quality care of cancer patients in the ICU.

\section{Objectives}

Describe the practice and analyze associated factors of life-sustaining treatment in the 8-bed ICU of a cancer specialized center.

\section{Methods}

Retrospective surveillance of adult patients (aged more than 18 years) admitted to the ICU from January/2010 to December/2014. For patients with more than one admission, only the last one was analyzed. Patients were divided into two groups: withdrawing or withholding life support (WWLS), and full life support, as suggested in the literature. Predictive factors of WWLS were identified using multivariate logistic regression analysis.

\section{Results}

Among 1511 patients admitted to ICU, 1309 (86,6\%) had solid tumors and $202(13,4 \%)$ had some kind of hematological malignancy. A small group had received stem-cell transplant $(4,9 \%)$. The median age was $62(18$, minimum and 90 , maximum) years and $58 \%$ were male. Thirteen percent $(196 / 1511)$ of patients had limitation of therapy (WWLS). We observed no difference in the annual prevalence during the study period $(\mathrm{p}=0,631)$. Primary reasons for the decision concerned malignancy status namely refractoriness to therapy and progressive disease. Hospital mortality was $39 \%(590 / 1511)$ and $33,2 \%$ of deaths

IPO - Porto, Porto, Portugal

(C) 2015 Tavares et al.; This is an Open Access article distributed under the terms of the Creative Commons Attribution License (http:// creativecommons.org/licenses/by/4.0), which permits unrestricted use, distribution, and reproduction in any medium, provided the original work is properly cited.
Table 1. Multivariate logistic regression analysis

\begin{tabular}{llll}
\hline Variable & Odds Ratio & $\mathbf{9 5 \%} \mathbf{C l}$ & $\mathbf{p}$ \\
\hline Age & 1,020 & $0,899-2,533$ & 0,008 \\
\hline Surgical status & 0,257 & $0,137-0,483$ & $<0,001$ \\
\hline Duration of mechanical ventilation & 1,004 & $1,002-1,006$ & 0,001 \\
\hline Length of stay in the ICU & 0,948 & $0,902-0,996$ & 0,036 \\
\hline APACHE $\geq 35$ & 4,327 & $2,789-6,713$ & $<0,001$ \\
\hline MODS & 3,926 & $2,569-6,001$ & $<0,001$ \\
\hline
\end{tabular}

occurred after WWLS. WWLS was independently associated with age, surgical status, length of mechanical ventilation, length of stay, APACHE score and organ failure (table 1).

\section{Conclusions}

End-of-life practice has been a routine in our center during the last 5 years (13\% of admissions). As demonstrated previously in general ICU, clinical parameters seem to be major determinants of WWLS decisions in cancer patients. Consensus statements may help physicians in the difficult task of end-of-life decision making.

Grant Acknowledgment

APEMCIO.

Published: 1 October 2015

\section{References}

1. Azoulay E, et al: End-of-life practices in 282 intensive care units: data from the SAPS 3 database. Intensive Care Med 2009, 35:623-630.

2. Sprung $C L$, et al: End-of-life practices in European intensive care units: the Ethicus Study. JAMA 2003 Aug 13, 290(6):790-7.

3. Truog $\mathrm{RD}$, et al: Recommendations for end-of-life care in the intensive care unit: A consensus statement by the American College of Critical Care Medicine. Crit Care Med 2008, 36(3):953-963.

\section{doi:10.1186/2197-425X-3-S1-A651}

Cite this article as: Tavares et al.: End-of-life decision making for cancer patients in an intensive care unit. Intensive Care Medicine Experimental 2015 3(Suppl 1):A651. 